\title{
High-resolution multispectral mapping facies on glacier surface in the Arctic using WorldView-3 data
}

\author{
Alvarinho J. Luis ${ }^{1 *}$, Shubham Singh ${ }^{2}$ \\ ${ }^{1}$ Polar Remote Sensing Section, Earth System Science Organization - National Centre \\ for Polar and Ocean Research, Ministry of Earth Sciences, Headland Sada, Vasco-da- \\ Gama, Goa - 403804, India \\ ${ }^{2}$ Forest Research Institute (deemed University), Dehradun, Uttarakhand, 248003, India
}

\begin{abstract}
Glaciers are important and sensitive part of our environment which can be used as indicator of global warming and climate change. Glacier facies represent distinct regions of a glacier surface characterized by near surface structure and density that develop as a function of spatial variations in surface melt and accumulation. The facies mapping aids in delineating different zones of the glacier, which are useful in computing glacier mass balance and modeling. In this study we tested traditional and advanced classification techniques on the Edithbreen glacier situated in Ny-Ålesund, Svalbard, using WorldView-3 and Landsat 8 OLI. The comparison of the accuracy was conducted using error matrices. Six measures of accuracy were derived from the error matrices and were compared with each other to find the method delivering the most adequate output for facies mapping. The pixel-based approach applied to Landsat- 8 data yielded higher accuracies $(>80 \%)$ when compared to that. The object-oriented classification revealed a much better accuracy and high kappa coefficient for both low and high-resolution datasets. The study clearly indicates that the object-oriented classification provides better results for glacier facies classification when high spatial resolution is used, but for lower spatial resolution, pixel-based methods are adequate.
\end{abstract}

Key words: Glacier facies, Landsat-8 OLI, WorldView-3, pixel-based classification, object-based classification

DOI: $10.5817 / \mathrm{CPR} 2020-1-3$

Abbreviations: ASTER - Advanced Spaceborne Thermal Emission and Reflection Radiometer, DEM - Digital Elevation Model, DN - Digital Numbers, EC - Error of Commission, ELA - Equilibrium Line Altitude, EO - Earth Observation, EoO - Error of Omission, ERS - European Space Agency, ERTS-1 - Earth Resources Technology Satellite, ETM - Enhanced Thematic Mapper, FLAASH - Fast Line-of-Sight Atmospheric Analysis of Spectral Hypercubes, GPR - Ground Penetrating Radar, GSD - Ground Sampling Distance, IGY - International Geophysical Year, IRS - Indian Remote Sensing

Received September 16, 2019, accepted May 5, 2020.

${ }^{*}$ Corresponding author: A. J. LUIS <alvluis1@gmail.com>

Acknowledgements: We thank NCPOR Director, for his motivation to promote research. We thank Mr. Sagar F. Wankhede for advice in the data processing, resolving the technical issues and useful guidance on spectral profiles/indices. This is the internship research undertaken at NCPOR-Goa by Shubham who was hosted by NCPOR. The computing facilities were funded by Ministry of Earth Sciences, Govt. of India. This is NCPOR contribution No.: J- 8/2020-21. 
Satellite, MD - Minimum Distance classification, MHD - Mahalanobis Distance classification, MXL - Maximum Likelihood Classification, MODTRAN - Moderate resolution atmospheric Transmission, MS - Multispectral, MSS - Multi-Spectral Scanner, NIR - Near-Infrared, OA - Overall Accuracy, OBC - Object-Based Classification, OBIA - Object-Based Image Analysis, OLI - Operational Land Imager, OOC - Object Oriented Classification Rule set, PA - Producer's Accuracy, PBC - Pixel Based-Classification, PC - Panchromatic, SAR - Synthetic Aperture Radar, SPOT- Satellite Pour l'Observation de la Terre, SWIR - Short-Wave Infrared, TERCAT - Terrain Categorization, TIRS - Thermal Infrared Sensor, TM - Thematic Mapper, TOA - Top-ofAtmosphere, UA - User's Accuracy, USGS - U.S. Geological Survey, VHR - Very High Resolution, VIS - Visible, WV- WorldView.

\section{Introduction}

A glacier, which is a persistent dense mass of ice that is constantly moving due to its own weight, is formed when accumulation of snow in an area is higher than ablation. Since the glacier is affected by long-term climatic changes in terms of altered air temperature, precipitation, cloud cover, so on, they are considered to be very sensitive indicators of climate change. Glacier facies represent distinct regions characterized by near surface structure and density that develop as a function of spatial variations in surface melt and accumulation. Glacier facies can be divided into zones each having unique spectral characteristics based on moisture, texture, hardness, impurities, stratification, grain size, (Jawak et al. 2018). The term facies was first distinguished by Benson (1961) and later modified by Muller (1962), Benson and Motyka (1979) and Paterson (1981) and later by Williams et al. (1991). Based on Paterson's nomenclature, glacier facies can be divided into dry zone, percolation zone, wet snow zone, superimposed ice zone, and bare ice zone (Paterson, 1981).

The climate warming in the Arctic affects the glacier mass budget (Box et al. 2019), and changes in the distribution of glacier facies are indicative of their response to the climate change. The state of the glacier and its response to the climate change can be assessed by comparing the extent of glacier facies at the end of melt season to that in the previous melt season, as at this time they are highly distinguishable, when the equilibrium line altitude (ELA) is in its annual maximum and glacier mass is in annual minimum (Benn and Evans 2014). Monitoring the spatial variability in snow and ice surface facies on glacier, ice sheet and ice caps can improve our understanding of changes in surface albedo and associated temperature and regional mass balance feedback mechanisms.

The surface signature in the spectral domain is used to characterize surface types and conditions using hard/soft classification, manual/supervised/unsupervised classification, parametric/nonparametric classification, spatial/spectral segmentation, pixel/ subpixel classification, and multispectral/ hyperspectral classification (Schowengerdt 2007). The choice of hard versus soft classification strategies depends on the natural characteristics of the boundary between two surface types, as well as on the sensor's spectral, spatial, and radiometric resolution. Manual delineation is adopted for accuracy assessments, ground data reference acquisition, or correction of other classifications. Supervised classification (such as MXL, MHD, MD, and OOC which are used in this work) involves intensive computer training on a priori operated selected categories to statistically represent spectral variations. 
In unsupervised classification, automatic differentiation of spectral clusters in feature space is done, based upon an initial selection of the number of classes desired. The use of a parametric algorithm assumes a certain statistical distribution and conditions associated with a spectral sample (e.g. normal distribution, homogeneity of variance). Image segmentation can also be accomplished using spatial information such as texture and spatial topology which is based upon contextual relationships between pixels or objects (Kääb et al. 2014). Finally, the spectral and spatial approaches can be combined for spatial-spectral segmentation. Quantifying the glacier features that contribute to the spectral signature of a mixed pixel leads to subpixel classification which is used to analyse the spectral properties of every pixel within the area of interest, without taking into account the

\section{Materials and Methods}

\section{Study area}

The study area is situated in the NyAllesund which is research town on the Brøgger peninsula on the shore of the Kongsfjorden Bay on the island of Spitsbergen in Svalbard, Norway. The area of Svalbard is about $63000 \mathrm{~km}^{2}$, with nearly $60 \%$ of the region covered with snow (Sand et al. 1991). Svalbard is mostly surrounded by drift ice during winter, but generally ice free in summer. It is situated in an active oceanic and atmospheric transport zone, where most of the ice from land enters into the Arctic Ocean through Fram Strait which is situated in west of Svalbard (Yamanouchi and Ørbæk 1995). The Svalbard archipelago has around 2100 glaciers covering an area of $33922 \mathrm{~km}^{2}$ (Pfeffer et al. 2014). The majority of glaciers are of sub-polar type (Hagen et al. 1993). The precipitation is around $400 \mathrm{~mm}$ annually at the western coast of Spitsbergen (Hagen et al. 1993). Svalbard consists of various types spatial or contextual information related to the pixel of interest (Nijhawan et al. 2016, Weih and Riggan 2010). In multispectral/ hyperspectral classification, approaches can be applied using a variable number of spectral bands. Some techniques are especially suited for hyperspectral data and a number of additional algorithms that are based upon spectral matching can be used (Lillesand and Kieffer 2000, Schowengerdt 2007).

The objectives of the study were (1) to test various methods of information extraction from spectral images to derive glacier facies at a test glacier in Svalbard, and (2) to compare traditional and advanced methods for glacier classification. In that process, we determined the overall accuracy of each classification method and tested various traditional and new customised indices available in literature for the classification of facies.

of glacier and large continuous ice masses are the most dominant type (Hagen et al. 1993).

In Svalbard, most of the glaciers are valley, cirque and piedmont glaciers based on morphological classification. It has been difficult to classify the complex glacier system because of the intricate network of ice that covers the large inland areas of Spitsbergen. Tyrrell (1922) used the term reticular glaciers and Ahlmann (1933) proposed transection glaciers for parts of the glaciated areas. Ice caps are common on the relatively flat islands on the eastern half of the Svalbard archipelago. Cirque glaciers are most common in the high mountain (alpine) ranges along the west coast. The majority of Svalbard's glaciers belong to the subpolar type because (1) the accumulation area is at the melting point, and the ablation zone is below the freezing point and partly frozen to the ground, and 
(2) large accumulations of ice (icings) in front of their termini are produced by the drainage of subglacial water throughout the entire winter season. In summer, however, melting takes place on the surface of all the glaciers, even at the highest elevations.
The study area is situated in the NyAlesund which is research town on the Brøgger Peninsula on the shore of the Kongsfjorden Bay on the island of Spitsbergen in Svalbard, Norway. The target area is Edithbreen which is a $3.27 \mathrm{~km}^{2}$ subpolar glacier situated at $78^{\circ} 51^{\prime} \mathrm{N}, 12^{\circ} 08^{\prime} \mathrm{E}$.

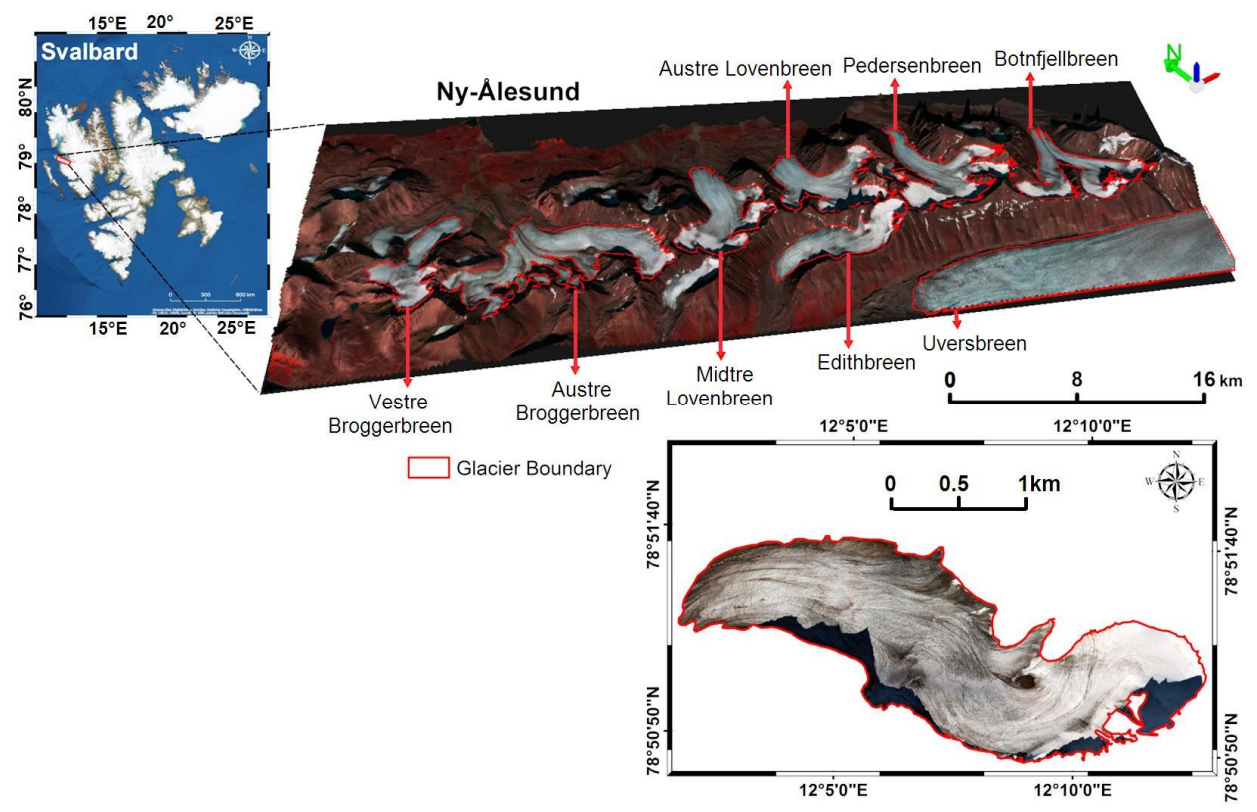

Fig. 1. The study area in the Svalbard region showing different glaciers. Edithbreen glacier is the focus of this study.

\section{Data}

WV-3 satellite-based optical imagery was used in this study. WV-3 is a sunsynchronous satellite orbiting at an altitude of $617 \mathrm{~km}^{2}$ with an inclination of $98^{\circ}$. The temporal resolution of $\mathrm{WV}-3$ is less than 1 day at $1 \mathrm{~m}$ GSD. The data was acquired on 10 August 2016 and was available in three tiles each having MS, PC and SWIR bands.
The details of the WV-3 bands are provided in Table 1. For comparison with WV-3 data we used Landsat-8 OLI data for the same date as WV-3. Landsat-8 OLI/TIRS was flown on Earth Resources Technology Satellite on February 2013. The configuration of the bands on Landsat- 8 is provided in Table 2.

\section{Methods}

The protocol adopted for pre- and postprocessing of the WV-3 data is depicted in Fig. 2. The image pre-processing generally involves radiometric calibration, geometric

correction/image registration, and atmospheric correction (Lu and Weng 2007, Sowmya et al. 2017). 


\begin{tabular}{|c|c|c|c|}
\hline \multirow{2}{*}{ Band Name } & \multirow{2}{*}{$\begin{array}{c}\text { Spectral range } \\
(\mathrm{nm})\end{array}$} & \multicolumn{2}{|c|}{ Ground Resolution (m) } \\
\hline & & Nadir & Off-nadir $\left(20^{\circ}\right)$ \\
\hline Panchromatic & $450-800$ & 0.31 & 0.34 \\
\hline Coastal $\quad(\mathrm{B} 1)$ & $400-450$ & 1.24 & 1.38 \\
\hline Blue & $450-510$ & 1.24 & 1.38 \\
\hline Green & $510-580$ & 1.24 & 1.38 \\
\hline Yellow & $585-625$ & 1.24 & 1.38 \\
\hline (B5) & $630-690$ & 1.24 & 1.38 \\
\hline Red Edge (B6) & $705-745$ & 1.24 & 1.38 \\
\hline NIR-1 $\quad$ (B7) & $770-895$ & 1.24 & 1.38 \\
\hline NIR-2 & $860-1040$ & 1.24 & 1.38 \\
\hline SWIR-1 $($ B9) & $1195-1225$ & 3.7 & 4.1 \\
\hline SWIR-2 (B10) & $1550-1590$ & 3.7 & 4.1 \\
\hline SWIR-3 (B11) & $1640-1680$ & 3.7 & 4.1 \\
\hline SWIR-4 (B12) & $1710-1750$ & 3.7 & 4.1 \\
\hline SWIR-5 (B13) & $2145-2185$ & 3.7 & 4.1 \\
\hline SWIR-6 (B14) & $2185-2225$ & 3.7 & 4.1 \\
\hline SWIR-7 (B15) & $2235-2285$ & 3.7 & 4.1 \\
\hline SWIR-8 (B16) & $2295-2365$ & 3.7 & 4.1 \\
\hline
\end{tabular}

Table 1. Details of bands of WorldView-3.

\begin{tabular}{|l|l|l|}
\hline \multicolumn{1}{|c|}{ Bands } & $\begin{array}{c}\text { Spectral range } \\
(\mathbf{n m})\end{array}$ & \multicolumn{1}{|c|}{$\begin{array}{c}\text { Ground resolution } \\
(\mathbf{m})\end{array}$} \\
\hline Band1 - Ultra Blue (coastal/aerosol) & $435-452$ & 30 \\
\hline Band2 - Blue & $452-512$ & 30 \\
\hline Band 3 - Green & $533-590$ & 30 \\
\hline Band 4 - Red & $636-673$ & 30 \\
\hline Band 5 - Near Infrared (NIR) & $851-879$ & 30 \\
\hline Band 6 - Shortwave Infrared (SWIR) 1 & $1566-1651$ & 30 \\
\hline Band 7 - Shortwave Infrared (SWIR) 2 & $2107-2294$ & 30 \\
\hline Band 8 - Panchromatic & $503-676$ & 15 \\
\hline Band 9 - Cirrus & $1363-1384$ & 30 \\
\hline Band 10 - Thermal Infrared (TIRS) 1 & $1060-1119$ & $100 *(30)$ \\
\hline Band 11 - Thermal Infrared (TIRS) 2 & $1150-1251$ & $100 *(30)$ \\
\hline
\end{tabular}

Table 2. Bands available in Landsat-8 OLI/TIRS.

The raw data, which consisted of 3 different tiles of DN file, were converted to at-sensor spectral radiance file using radiometric calibration tool of ENVI 5.3 (L3 Harris Geospatial, software). The radiometric calibration converts the raw DN val- ue to the at-sensor radiance value using the equation ([1] - ENVI User's Guide 2009): Radiance $=$ Gain $* \mathrm{DN}+$ offset values.

The relative motion of the earth, sensor and platforms, curvature of the earth, variation in altitude and position of platform 
and nonidealities in sensor is the major cause of this geometric distortion. The geometric correction generally consists of the two processes (Sowmya et al. 2017). First, correction of the geometric distortion caused due variation of sensor-Earth geometry. Second, conversion of data to real world coordinates. Radiometric correction is used for removal of sensor or environmental induced errors (Jensen 2015). The common induced radiometric errors are random bad pixels (shot noise), line-start/ stop problems, line or column drop-outs, partial line or column drop-outs and line or column striping (Jensen 2015). The radiometric calibration tool calibrate the image data (raw DN values) to radiance, reflectance or brightness temperature ([1]-ENVI User's Guide 2009).

The geometric correction was done using the Image Registration Workflow of ENVI 5.3. The centre tile was used as a base image and the geometrically distorted tile was used as a warp image. The first three tie point between the images was manually provided and the rest was computed automatically. The mosaicking was used to combine the multiple raster files into a single raster using seamless mosaicking ( $\mathrm{Lu}$ et al. 2014). Atmospheric correction is required to rectify scattering and absorption of the energy by the radiated light during the course of travel from object to the sensor and topographic attenuation. We used FLAASH tool developed by Air Force Philips Laboratory, Hanscom AFB and Spectral sciences, Incorporation ([2] - Flaash 2009, Jensen 2015). FLAASH provide selection for any of the standard MODTRAN model atmospheric and aerosol type specific to the scene and user requirement, and provide the user with a unique MODTRAN solution for each image ([3] - Exelis Quac and Flaash 2009). FLAASH has options for correction for pixel mixing due to scattering of surface reflected radiance.

The FLAASH output file has the scale of 10000 which was then corrected to the scale of $0-1$ using band math function in ENVI 5.3. The rescaling reflectance was done to obtain a comparable spectral profile of the surface characteristics to various spectral library and available literature. The geographic coordinate system (GCS_WGS_1984) was then converted to the Projected Coordinate System (WGS 1984_UTM_Zone_33N) using the Reproject Raster tool of the ENVI 5.3. The boundaries of the glaciers were manually digitized using ArcMap 10.4. Edithbreen glacier was then delineated from the study area using clip tool available in the Raster Management toolbox.

The PBC use only the spectral signature of a single pixel and possesses maximum spatial resolution. Because of the high spatial resolution of the WV-3, the PBC was appropriate to classify pixels of crevasses, debris, etc. PBC considers the satellite imagery to be a collection of pixels having spectral information unique to the land cover type. Therefore it is required to input spatial variables and transformation is achieved in the pixel-wise classification ( $\mathrm{Li}$ et al. 2014). The selection of ROI was done on the basis of visual interpretation, spectral reflectance, user knowledge and experience. The ROI for Edithbreen was created and the spectral reflectance was compared to previous studies (Jawak et al. 2019) and spectral libraries were used to assign class to each ROI. The supervised classification of the glacier was performed using the TERCAT tool of the ENVI 5.3 into 10 classes which are crevasses, debris, dry snow, melting ice, offglacier, percolation snow, shadow, water stream, wet snow, dirty ice. We used advanced supervised classifiers: MXL, MHD, and $\mathrm{MD}$, as these have been reported to deliver higher accuracies in the previous studies (Jawak et al. 2018, 2019).

For the OOC, we adopted multiresolution segmentation using Trimble eCognition Developer 9 ([4] - eCognition Developer 2014). The image was segmented by using two different scale parameters. One 
parameter was set to include the crevasses and water stream named as OOC- 1 and the other do not comprises of crevasses and water stream named as OOC-2. This was done to check whether the smaller objects affect the classification accuracy or not. The weightage for each band for OOC-1 and OOC-2 were as follows: Coastal: 2 , Blue: 3, Green: 4, Yellow: 2, Red: 3, Red Edge: 2, NIR-1: 3, NIR-2: 2, SWIR-1 and SWIR-2: 3, SWIR-3, SWIR-4, SWIR-5: 2, and SWIR-6, SWIR-7, SWIR-8: 1. The scale parameter for OOC-1 and OOC-2 was set to 2 and 10, respectively, while the shape and compactness for both were assigned the value of 0 and 0.9 , respectively. The segmented image was subsequently used for developing customized spectral index ratios (SIRs) (Table 3) to facilitate the optimal identification and extraction of the facies. The bands used to develop the indices were selected after a repetitive trialand-error method to achieve the best possible combination in accordance to the spectral response pattern of the various targets (facies) and the band characteristics. The utilization of indices to extract facies creates the need for assigning thresholds. Therefore, one particular threshold from a single index or a combination of thresholds from more than one index can be considered to be a unique specification of the spectral characteristics of a particular facies (Jawak et al. 2017).

\begin{tabular}{|c|c|}
\hline Spectral Index & Mathematical expression \\
\hline NDSI & $\frac{\mathrm{B} 3-\mathrm{B} 9}{\mathrm{~B} 3+\mathrm{B} 9}$ \\
\hline NDSII & $\frac{\mathrm{B} 5-\mathrm{B} 9}{\mathrm{~B} 5+\mathrm{B} 9}$ \\
\hline S3 & $\frac{\mathrm{B} 7(\mathrm{~B} 5-\mathrm{B} 9)}{(\mathrm{B} 7+\mathrm{B} 5)+(\mathrm{B} 7+\mathrm{B} 9)}$ \\
\hline NIR/SWIR & $\frac{\mathrm{B} 7}{\mathrm{~B} 9}$ \\
\hline
\end{tabular}

Table 3. Customized Spectral Index Ratios used in the study. Note: NDSI: Normalized-Difference Snow Index, NDSII: Normalized-Difference Snow Index I, S3: new Snow Index, NIR/SWIR: Near-Infrared/Short-Wave Infrared.

The accuracy assessment was done by using error matrix. The reference points were generated using the unclassified atmospherically corrected imagery of the glacier without considering any of the classified images of either $\mathrm{PBC}$ or $\mathrm{OBC}$ to avoid any bias. Ten reference points for each class was created using shapefile in ArcMap 10.4, resulting in overall 100 reference points. There was no ground truth available close as the date of satellite im- age acquisition, so an equalized random sampling approach was adopted and validation was performed based on interpretation of the spectral plots and visual analysis (Keshri et al. 2009). For OBC output, the accuracy assessment was done using ArcMap 10.4 by manually checking each reference points and generating the error matrix. The statistical measures used for accuracy assessment were OA, PA, UA, EC, EoO, and kappa coefficient. 


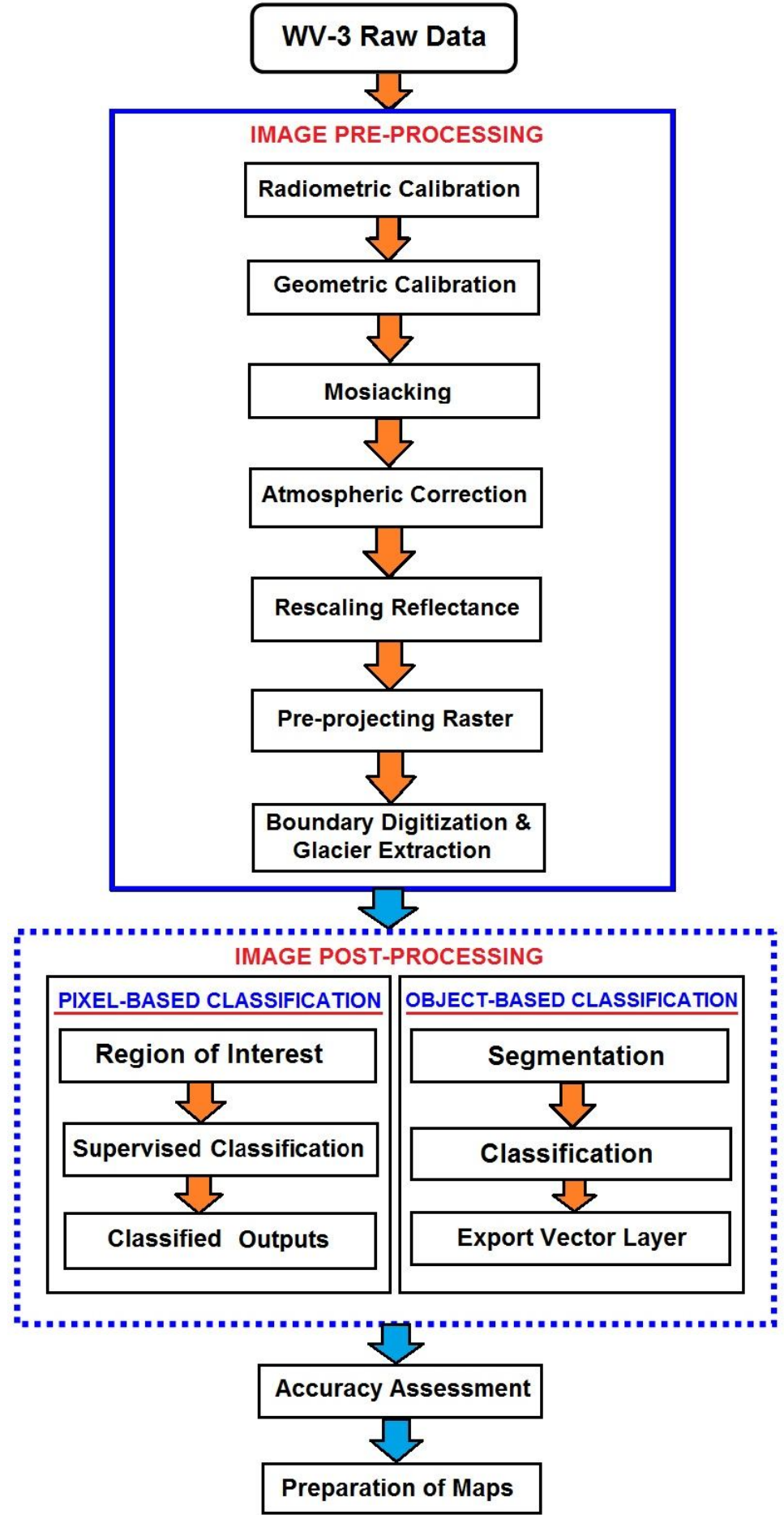

Fig. 2. The protocol followed for pre- and post-processing of the WV-3 data. 


\section{Results}
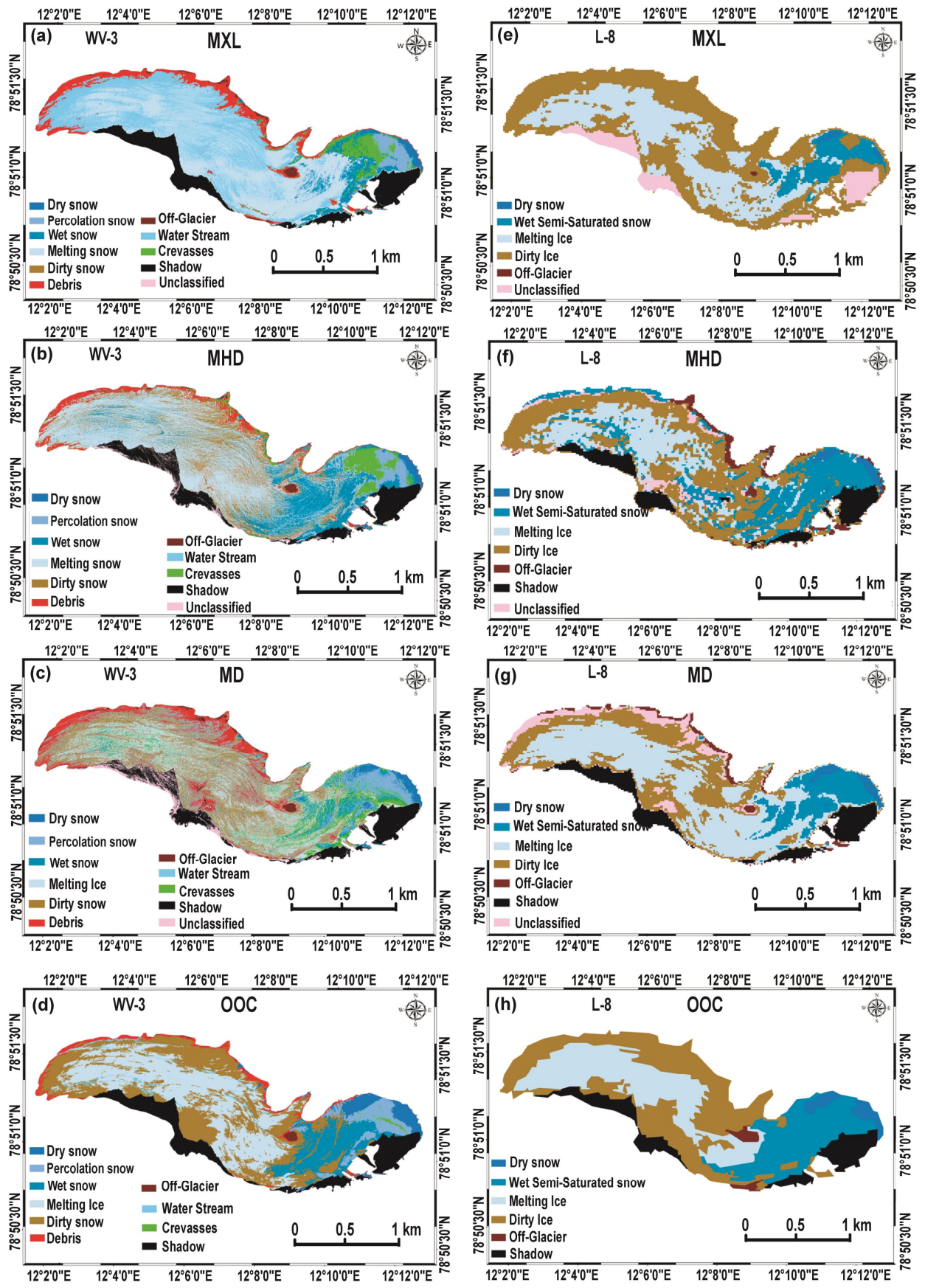

Fig. 3. Classification output maps using MXL, MHD, MD and OOC on WV-3 and L-8 imagery for Edithbreen glacier. 
Fig. 3 depicts the output maps using the supervised classification consisting of MXL, MHD, MD, and OOC using WV-3 (left panel) and L-8 (right panel). The statistical measures such as overall accuracy and kappa are shown in Fig. 4. The comparative analysis of the results indicated that the $\mathrm{PBC}$ methods were inferior to the OOC techniques. Among the PBC, the MXL classifier outperformed (overall accuracy: $83 \%$, карpa: 0.81 ) with lowest error of commission $(12.48 \%)$ and the error of omission at $17 \%$ with percentage for different classes as follows: $15 \%$ for melting ice, $14 \%$ water streams, $13 \%$ each for debris and percolation snow, $10 \%$ each for dry snow and shadow, $11 \%$ for off-glacier, $8 \%$ for crevasses, and $6 \%$ for wet snow (Figs. 3a and 4). Among the other classifiers MD underperformed (overall accuracy: 55\%, кappa: 0.50 ) with highest error of commission (49.30\%) and error of omission $(45.00 \%)$ (Fig. 3c). The performance of MHD was marginally better (overall accuracy: 67\%, kappa: 0.64, error of commission: $28.21 \%$ ) and error of omission: $33.00 \%$ ), with percentage of the different classes as follows: $18 \%$ for percolation snow, $11 \%$ each for melting ice and off-glacier, $12 \%$ each for shadow and wet snow, 9\% for dry snow, 7\% each for unclassified and debris, $4 \%$ for water stream and dirty ice, and 5\% for crevasses (Fig. 3b).

The OOC method using on WV-3 (Fig. 3d) has outstanding performance (overall accuracy: 96\%, кappa: 0.96) with least error of commission $(3.78 \%)$ and error of omission $(4.00 \%)$ with percentage for different classes as follows: $12 \%$ for debris, $10 \%$ each for crevasses, melting ice, offglacier, percolation snow, shadow, water stream, dirty ice, and $9 \%$ for wet snow. Likewise, OOC was applied to L-8 yielded overall accuracy: $96.67 \%$, and каppa: 0.96 with least error of commission $(2.78 \%)$ and error of omission (3.33\%) (Figs. 3h and 4 ).

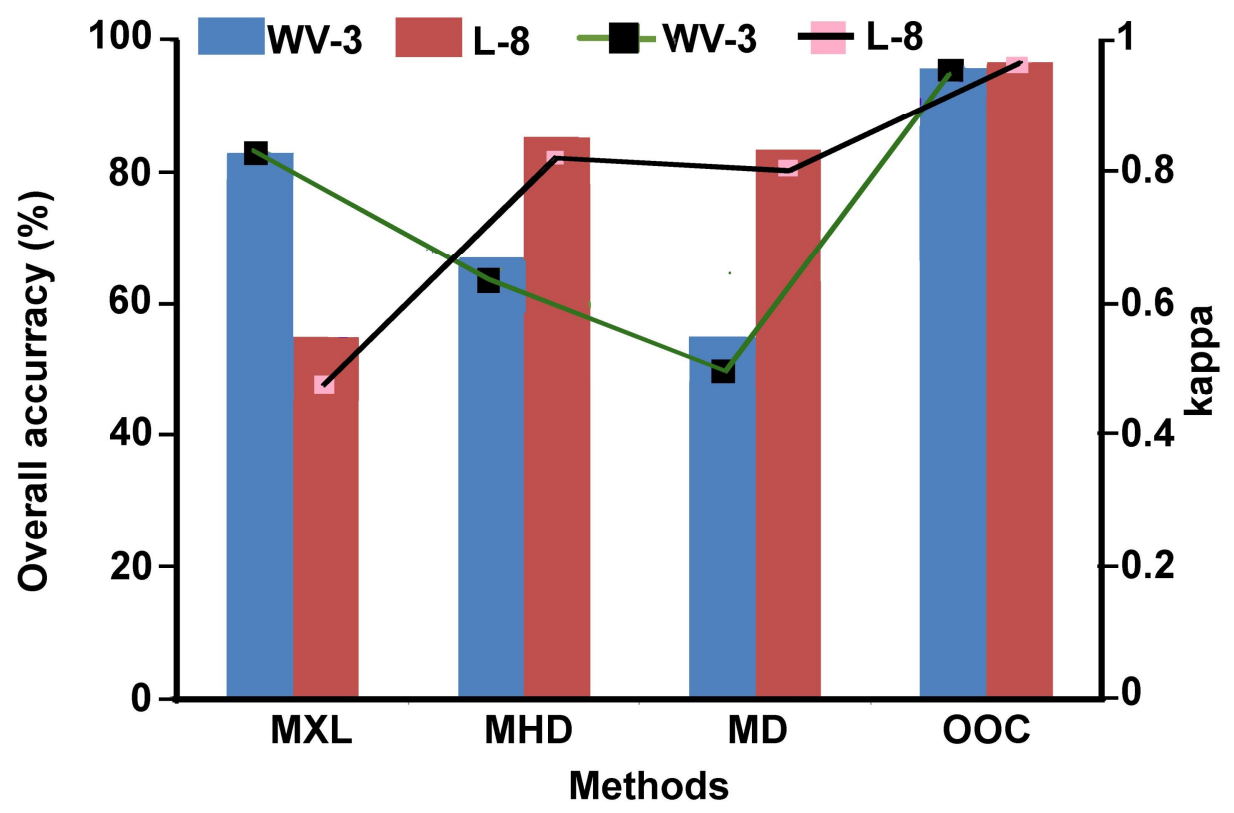

Fig. 4. Measures of accuracy (overall accuracy and kappa) for supervised classification. 


\section{Discussion}

The accuracy of the classification results obtained by using L-8 was found higher than that obtained by using WV-3 data, but the classes formed in the WV-3 dataset was higher (Fig. 3a-d) than that of L-8 (Figure 3e-h), owing to high resolution of the WV-3 which allowed selection of more classes than L-8. The study showed that the higher resolution is better to select small facies and classes such as wet snow, percolation snow, crevasses and water stream. These small classes were not quite visible in the L-8 data due to the low spatial resolution, they were not classified. A maximum of nine classes were formed using the WV-3 data, but only six classes were formed using the L-8 (compare Fig. 3a-d and Fig. 3e-h). The percolation snow and wet snow were not visibly detected in L-8 data and were classified commonly as the Wet Semi-Saturated Snow (Figure 3e-h). Debris was also undetected in L-8 and was confused with the OffGlacier, but due to the higher reflectance in SWIR it was considered as Off-Glacier.

Among the PBC methods applied for L-8 data, higher accuracy was achieved for the MHD classifier (Fig. 3f), but the WV-3 data showed higher accuracy for MXL classifier among the PBC methods (Fig. $3 a)$. This suggests that the spatial resolution play a significant role on the classification results of glacier facies. The accuracy obtained from the OOC methods surpasses that from the PBC classification for both the datasets (Figs. 3d and $3 \mathrm{~h}$ ). This indicates that advanced classification has supremacy over the traditional classification system.

Rastner et al. (2014) compared glacier classification by using the $\mathrm{OBC}$ and $\mathrm{PBC}$ techniques in three test regions and found that the OBC performed 3\% better than the PBC. For PBC they mapped clean ice and snow using band ratio algorithms by utilizing VIS and SWIR bands. For OBC, the image was segmented into objects using a multi-resolution segmentation algorithm and was then classified by applying thresholds to the ratio of VIS and SWIR. The accuracy assessment was carried out to compare the performance of the two techniques. Jawak et al. (2018) compared the $\mathrm{OBC}$ and $\mathrm{PBC}$ methods by using very high resolution WV-2 imagery, and reported an overall accuracy of $97.14 \%$ and $74.28 \%$, respectively. Their study suggests that the OBC approach is far more accurate than the PBC approach.

This study demonstrated that traditional pixel-based classifiers work more efficiently on moderate resolution such as L-8, but the accuracy decreased when high resolution satellite imagery was used. This is caused due to "salt and pepper (speckles)" effect created in the classification of high resolution dataset resulting in the mixed pixels. At this point it is prudent to mention the advantages of object-based approach over the pixel-based approach. First, the change of classification units from pixels to image objects reduces within-class spectral variation and generally removes the salt-and-pepper effects that are typical in PBC. Second, a large set of features characterizing object's spatial, textural, and contextual properties can be derived as complementary information to the direct spectral observations to potentially improve classification accuracy (Guo et al. 2007). The results of OA for OOC using WV-3 data showed $96.00 \%$ ) which was at par with L-8 $(96.67 \%)$. Thus, the advance classifier can be utilized for achieving higher efficiency when classification is done using the high resolution data. Although, if moderate or coarser resolution dataset is used then the PBC would be enough to produce optimum result but higher resolution dataset requires the utilization of advanced classification methods.

Paul et al. (2016) tested various spectral band combinations to map glacier and compared the glacier mapping capabilities of 
the Sentinel 2 and Landsat OLI using raw DNs. They also mapped snow and bare ice using TOA reflectance from Sentinel 2 data. Their study showed that the higher resolution allows for more precise digitization thus providing more accurate delineation of the glacier area. Paul et al. (2002) compared TM-derived glacier areas with SPOT pan imagery, IRS-1C and Ikonos and inferred that the areas derived from high resolution imagery were found to be smaller, as compared to Landsat TM. Their study also suggested the use of the threshold ratio images for efficient and automated glacier mapping.

The applicability of OLI and TIR sensor on board L- 8 satellite was evaluated by Bhardwaj et al (2015). Their study demonstrated the use of an algorithm that employ data in Blue, NIR, SWIR and TIR bands for automated glacier facies and supraglacier debris mapping; they validated the results using the field based observations. The study classified the glacier surface into crevasses, clean ice, dirty glacier ice/mixed pixels (due to seasonal snow), slush zone, snow and supra-glacial debris. The debris covered glacier was delineation using OBIA by combining SAR coherence data with optical and topographical data (Robson et al. 2015) in the Manaslu region of Nepal using the L-8 imagery. They semiautomatically mapped the clean ice with an accuracy of $93.3 \%$ (6.7\% error) and the debris-covered portions to an accuracy of $83.3 \%$ (error: $16.7 \%$ ) given accuracy of $91.1 \%$ over the entire glacier. The study also suggested the use of high resolution DEM and temporarily consistent data to improve the accuracy.

Derivation of glacier surface characteristics using hyperspectral datasets derived from Hyperion sensor onboard EO-1 satellite had been carried out elsewhere (Gore et al. 2017) using SAM classifier for snow mapping. The accuracy assessment was done using validation of the classified images using spectral library (USGS and ASTER) and field-based spectral radiometric measurements. The facies derivations using medium resolution satellite such as L-8 OLI still has a potential for mapping facies as demonstrated in this work using a few classifiers. But short time span of data of L-8 OLI is still a challenge for monitoring long term change detection studies, so a time series is recommended.

\section{Future Directions}

The performance of OOC was found higher than that of PBC. Use of spectral indices suggests that better results for glacier facies classification can be achieved. This study demonstrated that high resolution data improved classification performance combined with the OOC, but moderate or coarser resolution data can be combined with PBC for improving the accuracy. Studies involving mapping of smaller

classes such as distinct percolation snow zone, wet snow zone, crevasses and water stream use of high resolution imagery becomes a compulsion. The future work should include a detailed ground survey, temporal study of facies to detect changes using remote sensing data, more advanced classification techniques and customized spectral indices for improving facies extraction.

\section{References}

Ahlmam, H. W. (1933): Scientific results of the Swedish-Norwegian Arctic Expedition in the summer of 1931: Part VIII. Glaciology. Geografiska Annaler, 15(4): 261-295. 
Bhardwaj, A., Joshi, P. K., Snehmani, S. L., Singh, M. K., Singh, S. and Kumar, R. (2015): Applicability of Landsat 8 data for characterizing glacier facies and supraglacial debris. International Journal of Applied Earth Observation and Geoinformation, 38: 51-64. https://doi. org/10.1016/j.jag.2014.12.011.

Benn, D., Evans, D. J. A. (2014): Glaciers and glaciation. Routledge.second Edition, 789 p.

Benson, C.S. (1961): Stratigraphic studies in the snow and firn of the Greenland ice sheet. Folia Geographica Danica, 9: 13-37.

Benson, C. S., MотyKa, R. J. (1979): Glacier-volcano interactions on Mt. Wrangell, Alaska. University of Alaska, Fairbanks. Geophysical Institute, Annual Report, pp. 1-25.

Box, J. E, Colgan, W. T., Christensen, T. R., Schmidt, N. M., Lund, M., Parmentier, F-J. W., Brown, R., Bhatt, U. S., Euskirchen, E. S., Romanovsky, V. E., Walsh, J. E., Overland, J. E., Wang, M., Corell, R. W., Meier, W. N., Wouters, B., Mernild, S., Mård, J., Pawlak, J. and OlSEN, M. S. (2019): Key indicators of Arctic climate change: 1971-2017. Environmental Research Letters, 14: 1-18.

Gore, A., Mani, S., Hari, H. R., Shekhar, C. and Ganju, A. (2017): Glacier surface characteristics derivation and monitoring using Hyperspectral datasets: a case study of Gepang Gath glacier, Western Himalaya. Geocarto International, 6049: 1-20. https://doi.org/10.1080/ 10106049.2017.1357766.

Guo, Q., Kelly, M., Gong, P. and Liu, D. (2007): An object-based classification approach in mapping tree mortality using high spatial resolution imagery. GIScience \& Remote Sensing, 44: 24-47.

Hagen, J. O., Liestøl, O., Roland, E. and Jørgensen, T. (1993): Glacier atlas of Svalbard and Jan Mayen. Editor: Annernor Brekke. Nor. Polarinst. Medd. 129. Norwegian Polar Institute, Oslo. 32 p.

JAWAK, S. D., WANKHEDE, S.F. and LuIS, A. J. (2017): Prospective of high resolution worldview-2 satellite data for geospatial surface facies mapping of an alpine glacier. Proceedings of the Asian Conference on Remote Sensing 2017. https://www.dropbox.com/sh/z0pws7ul29n7v1d/ AACaV9rFNcF01xNGnWwwgmF_a/177.pdf?dl=0.

JaWAK, S.D., WANKhede, S. F. and Luis, A. J. (2018): Comparison of pixel and object-based classification techniques for glacier facies extraction. The International Archives of the Photogrammetry, Remote Sensing and Spatial Information Sciences, Volume XLII-5, pp. 543548.

JAWAK, S.D., WANKHEDE, S. F. and Luis, A. J. (2019): Explorative study on mapping surface facies of selected glaciers from Chandra Basin, Himalaya using WorldView-2 data. Remote Sensing, 11: 1207. doi:10.3390/rs11101207.

JENSEN, J. R. (2015): Introductory digital image processing: A remote sensing perspective. Prentice Hall Press. Brigham Young University. 656 p.

KäÄB, A., Bolch, T., Casey, K., Heid, T., Kargel, J.S., Leonard, G.J, Paul, F. and Raup, B.H. (2014): Glacier mapping and monitoring based on spectral data. In: Kargel, Jeffrey S; Leonard, Gregory J; Bishop, Michael P; Kääb, Andreas; Raup, Bruce H. (Eds.): Global Land Ice Measurements from Space. Heidelberg: Springer, pp. 75-104.

Keshri, A., Shukla, A. and GuPTA, R. (2009): ASTER ratio indices for supraglacial terrain mapping. Internation Journal of Remote Sensing, 30(2): 519-524. doi:10.1080/0143116080 238545

Lillesand, T., KiefFer, R. (2000): Remote Sensing and Image Interpretation. Fourth Edition, John Wiley \& Sons, New York. 736 p.

Li, M.; ZANG, S., Zhang, B., Li, S. and Wu, C. (2014): A review of remote sensing image classification techniques: The role of spatio-contextual Information. European Journal of Remote Sensing, 47: 389-411.

Lu, D., WenG, Q. (2007): A survey of image classification methods and techniques for improving classification performance. International Journal of Remote Sensing, 28(5): 823-870. doi: $10.1080 / 01431160600746456$

Lu, T., Li, S. and Fu, W. (2014): Fusion based seamless mosaic for Remote Sensing images. Sensing and Imaging, 15: 101. doi: 10.1007/s11220-014-0101-0 
MÜLLER, F. (1962): Zonation in the accumulation area of the glaciers of Axel Heiberg Island, N.W.T., Canada. Journal of Glaciology, 4: 302-311.

NiJHAwan, R., Garg, P. and THAKUR, P. (2016): A comparison of classification techniques for glacier change detection using multispectral images. Perspectives in Science, 8: 377-380.

Paterson, W.S.B. (1981): The physics of glaciers. Second Edition. New York, Pergamon Press. 480 p. https://doi.org/10.1016/C2009-0-14802-X

Paul, F., Huggel, C., KäÄB, A., Kellenberger, T. and Maisch, M. (2002): Comparison of TMderived Glacier areas with higher resolution data sets. Proceedings of EARSeL-LISSIGWorkshop Observing our Cryosphere from Space, Bern, pp. 15-21.

Paul, F., Winsvold, S.H., KäÄB, A. and Nagler, T. (2016): Glacier remote sensing using Sentinel-2. Part II: Mapping glacier extents and surface facies, and comparison to Landsat-8. Remote Sensing, 8(7): 575. https://doi.org/10.3390/rs8070575.

Pfeffer, W. T., Arendt, A. A., Bliss, A., Bolch, T., Cogley, J. G., Gardner, A. S., Hagen, J.O., Hock, R., Kaser, G., Kienholz, C., Miles, E. S., Moholdt, G., Mölg, N., Paul, F., Radić, V., Rastner, P., Raup, B.H., Rich, J. and Sharp, M. J. (2014): The Randolph Glacier Inventory: a globally complete inventory of glaciers. Journal of Glaciology, 60: 537-552.

Rastner, P., Bolch, T., Notarnicola, C. and Paul, F. (2014): A comparison of pixel- and object-based glacier classification with optical satellite images. IEEE Journal of Selected Topics in Applied Earth Observations and Remote Sensing, 7: 984-993. doi: 10.1109/JSTARS. 2013.2274668.

Robson, B. A., Nuth, C., Dahl, S. O., Hölbling, D., Strozzi, T. and Nielsen, P. R. (2015): Automated classification of debris-covered glaciers combining optical, SAR and topographic data in an object-based environment. Remote Sensing Environment, 170: 372-387. doi: 10.1016/ j.rse.2015.10.001.

SAND, K., Hagen, J. O., RePp, K. and BerntSen, E. (1991): Climate-related research in Svalbard (CONF-9006128-Vol2). Severin, B.A.B. (Ed.). United States. 404 p.

SCHOwENGERDT, R. A. (2007): Remote Sensing: Models and Methods for Image Processing, Third Edition, Academic Press, San Diego, CA (ISBN 0-12-628981-6). 560 p.

Sowmya, D. R., Shenoy, P. D. and Venugopal, K. R. (2017): Remote sensing satellite image processing techniques for image classification: A comprehensive survey. International Journal of Computer Applications, 161(11): 24-37.

Tyrrell, G.W. (1922): The glaciers of Spitsbergen: The Transactions of the Geological Society of Glascow, v. XVII, pt. 1, pp. 1-49.

WEIH, R.C. JR., RIGGAN, N.D. JR. (2010): Object-based classification vs. pixel-based classification: comparative importance of multi-resolution imagery. Proceedings of GEOBIA 2010: Geographic Object-Based Image Analysis, 38 (2010), 6 p.

Williams, R. S., Hall, D. K. and Benson, C. S. (1991): Analysis of glacier facies using satellite techniques. Journal of Glaciology, 37: 120-128.

YAMANOUCHI, T., ØRBÆK, J.B. (1995): Comparative study of the surface radiation budget at NAlesund, Svalbardand Syowa station, Antarctica, 1987. Proceedings of the NIPR Symposium on Polar Meteorology and Glaciology, 9: 118-132.

\section{Web sources / Other sources}

[1] ENVI User's Guide (2009)

[2] Flaash (2009): Atmospheric correction module quac and flaash user's guide version 4.7 ITT Visual Information Solution Inc.

[3] Exelis Quac and Flaash (2009): Atmospheric Correction Module: QUAC and Flaash User.

[4] eCOGNITION DEVELOPER, T. (2014): 9.0 User Guide. Trimble Ger. GmbH Munich, Germany. 